\title{
Globalization and Smallholders \\ The Adoption, Diffusion, and Welfare Impact of Non-traditional Export Crops in Guatemala
}

\section{Calogero Carletto, ${ }^{1}$ Angeli Kirk, ${ }^{2}$ Paul Winters, ${ }^{3}$ and Benjamin Davis ${ }^{4}$}

February 2008

\begin{abstract}
This paper uses a duration analysis based on adoption data spanning over 25 years from six communities in the Central Highlands of Guatemala to explore how household characteristics and external trends play into both the adoption and diffusion processes of non-traditional exports among smallholders. Adoption was initially widespread and rapid, which led NTX to be hailed as a pro-poor success, reaching all but the smallest landholders. However, over time more than two-thirds of the adopters eventually dropped out from NTX production. Based on the analysis, NTX production $\quad . . /$.
\end{abstract}

Keywords: globalization, land, smallholders, non-traditional exports

JEL classification: J43, N56, O13

\section{Copyright (C) UNU-WIDER 2008}

${ }^{1}$ Senior Economist at the World Bank, ${ }^{2}$ Consultant, Agricultural and Development Economics Division, FAO, ${ }^{3}$ Associate Professor at American University Economist, ${ }^{4}$ Agricultural and Development Economics Division, FAO.

This is a revised version of a paper originally prepared for the UNU-WIDER project conference on The Impact of Globalization on the Poor in Latin America, directed by Professors Machiko Nissanke and Erik Thorbecke. The conference was organized in Rio de Janeiro, in collaboration with Pontifícia Universidade Católica do Rio de Janeiro, 23-24 September 2006.

UNU-WIDER gratefully acknowledges the financial contribution of the Finnish Ministry of Foreign Affairs to this project, and the contributions from the governments of Denmark (Royal Ministry of Foreign Affairs), Norway (Royal Ministry of Foreign Affairs), Sweden (Swedish International Development Cooperation Agency-Sida) and the United Kingdom (Department for International Development) to the Institute's overall research programme and activities. 
appeared to have delivered less prosperity to adopters than initially promised. While smallholders may be enticed into entering into NTX markets when conditions are favourable, they may lack the capacity to overcome difficulties that inevitably arise in complex types of cultivations and in highly variable global agricultural markets. Governmental and non-governmental organizations can attempt to mitigate these difficulties, but market forces may overwhelm these efforts, with some adopters still unable to compete in global markets.

\section{Acknowledgements}

We would like to thank Erik Thorbecke, Alejandro de la Fuente Meraz and other participants at the UNU-WIDER conference 'The Impact of Globalization on the Poor in Latin America', held in Rio de Janeiro in September 2006 for comments. We would also like to thank the FAO-Norway Partnership Programme and the World Bank for funding.

The World Institute for Development Economics Research (WIDER) was established by the United Nations University (UNU) as its first research and training centre and started work in Helsinki, Finland in 1985. The Institute undertakes applied research and policy analysis on structural changes affecting the developing and transitional economies, provides a forum for the advocacy of policies leading to robust, equitable and environmentally sustainable growth, and promotes capacity strengthening and training in the field of economic and social policy making. Work is carried out by staff researchers and visiting scholars in Helsinki and through networks of collaborating scholars and institutions around the world.

www.wider.unu.edu publications@wider.unu.edu

UNU World Institute for Development Economics Research (UNU-WIDER)

Katajanokanlaituri 6 B, 00160 Helsinki, Finland

Typescript prepared by Lisa Winkler at UNU-WIDER

The views expressed in this publication are those of the author(s). Publication does not imply endorsement by the Institute or the United Nations University, nor by the programme/project sponsors, of any of the views expressed. 


\section{Introduction}

As developing countries continue on the path of economic liberalization, there is a compelling need to ensure that the benefits of globalization reach poor rural communities. Increased commercialization of agriculture and diversification into nontraditional exports (NTXs) is one strategy that has often been advocated as a way for developing countries to use their comparative advantage in lower labour costs and to achieve growth in the agricultural sector. Given the predominantly rural nature of most developing countries and the preponderance of poor people in these areas, high-value agricultural production is considered the ideal mechanism to extend the benefits of globalization directly to the rural poor: 1 Allowing poor farmers to shift into the export sector and take advantage of internationally demand driven prices that are higher relative to traditional crops may reduce inequality while fostering overall economic growth (Nissanke and Thorbecke 2007).

However, the factors that drive NTX adoption, the extent to which the economic gains from NTX adoption (or the resulting spillovers) actually reach the poor and whether such anti-poverty strategies have been successful in the long run remain open empirical questions. Information asymmetries, differentiated risks, constrained access to credit and limited assets, as well as other market imperfections, appear to put poorer people at a disadvantage in the adoption of more profitable but riskier export crops. Even in those rare cases in which adoption is apparently more inclusive of the poor, cumulative events in both the production and marketing of NTXs have seldom favoured the more vulnerable in the medium and long run.

This is partially because globalization brings about its own set of risks that influence the ability of households to successfully maintain production. First, price fluctuations in the international market may exceed those in the domestic market for alternative crops such as staples and other traditional crops. Furthermore, NTX prices may have a greater tendency to deteriorate over time as high prices draw in producers not just from the same country but from other developing countries seeking to enter into lucrative markets. This bandwagon effect can lead to price deterioration, resulting in only the most efficient producers remaining in the market, which are less likely to be the poorest producers. Second, uncertainty may be exacerbated by policies of importing countries that influence the ability to obtain access to global markets. Policies related to product quality and production practices in receiving countries such as the USA can lead to collective punishment of exporters leading to uncertainty about market access. This will hurt those that are most likely to be vulnerably to such uncertainty, particularly those with limited assets.

A much studied experience that, at least initially, appeared to overcome the potential problems is the diffusion of NTX production among smallholders in the Central Highlands of Guatemala. The area experienced a boom in non-traditional exports starting in the early 1980s that initially led to large increases in earnings among adopters (von Braun et al. 1989). In addition, the positive spillover effects of NTX adoption on

1 Ravallion and Chen (2004) find that growth in agriculture is more effective at reducing poverty compared to growth in the secondary and tertiary sectors. 
staple food production seemed temporarily to put to rest concerns over the potentially negative impact of NTX production on food security and malnutrition. However, despite apparent gains in income and food production deriving from increases in productivity, no visible positive effect on nutrition was found (von Braun et al. 1989). In addition, medium term trends raised concerns about the sustainability of NTX for the majority of adopters (Carletto et al. 1999; Carletto 2000).

Contrary to previous agro-export booms in Guatemala, NTX cultivation spread among all types of farmers but the very smallest, potentially making it an effective, nearly allinclusive poverty alleviation mechanism, as high export prices boosted household incomes. This and other similar experiences in the region appeared to be good examples of how the benefits of globalization could be transferred to poorer households. Much of the expansion in cultivation and marketing was assisted by an agricultural cooperative, Cuatro Pinos, established at the end of the 1970s with donor assistance. However, as reported in Carletto et al. (1999), a wide range of problems beginning in the early 1990s led to a significant drop in profitability that caused many of the smaller and resource poor farmers to withdraw from export crop production. A set of these problems came through the agronomics of intense NTX cultivation as farmers were confronted with significant declines in soil quality and increasing pesticide resistance.

Yet, an even greater source of problems was related to the global market for NTXs. International NTX prices began to deteriorate over time as additional producers entered into the export market. Between 1992 and 2002, the total value of exports of vegetables from Central America and the Caribbean more than doubled from US\$956 million in 1992 to US\$2.2 billion in 2001. Although for Guatemala the increase in the total value of exports was even larger, from US\$14 million to US\$44 million, the total volume exported went from 42,000 to 271,000 tons over the same period, indicating a dramatic decline in average prices (FAO 2007). Along with the price declines, frequent import bans from the USA in the 1990s over product quality issues led to growing price uncertainty. Furthermore, growers were also saddled with the prohibitive costs of pesticide residue spot checks that were required if the producers wanted to continue to export to the USA.

Problems in the global market were compounded by declining support provided by Cuatro Pinos, as the organization was beset with management problems, increased default on the credit it had provided and a decline in the quality of technical assistance it offered (Carletto et al. 1999). Thus, while global market conditions for NTXs deteriorated, the support that smallholders received to help access the global market weakened as well.

Over the course of the years, several NTXs have been introduced in the study area, but the crop with highest potential - as well as raising most concerns - is snowpeas. By 2000, Guatemala was cultivating 4,550 hectares in snowpeas, employing more than 32,000 people. Over 80 per cent of the households in our sample reported growing snowpeas at some point in time since 1979. However, of these adopters, 72 per cent had withdrawn 2 from cultivation by 2005 . On average, snowpeas adopters cultivated the

2 Farmers may occasionally withdraw from production for short periods of time but continue over the long run. For the purposes of this paper, withdrawal refers to those who have stopped cultivation for a period of at least three years. 
crop for 14.5 years. 3 Although adoption was widespread, virtually no one specializes in snowpeas cultivation, preferring instead a diversified crop portfolio, always including milpa, the traditional intercropping of maize and beans. Among farmers still growing snowpeas in the 2004-2005 season, the average area cultivated in snowpeas was 2.7 cuerdas $^{4}$, just under 30 per cent of their total cultivated land. Diseconomies of scale in production, due in part to moral hazard problems with hired labour, have been cited as a possible reason for the low production levels (von Braun et al. 1989; Carletto et al. 1999). High input costs, combined with limited access to credit, is another.

Studies of the adoption of agricultural technologies have generally focused on the dichotomous decision to participate in new types of production by estimating limited dependent variable models. 5 Some extensions have included modelling the extent of adoption using a censored regression specification (Barham et al. 1995; Winters et al. 2004). Although informative, these types of specifications ignore the dynamic nature of the adoption process, which is more properly modelled as a repeated decision conditional on past occurrences and affected by changing conditions over time. In addition, dichotomous models fail to provide information on the diffusion of adoption and thus on the role played by changing conditions on the spreading, or thinning out of the phenomenon. In this study, we model both the decision to adopt NTXs, as well as the decision to abandon its production, using a single spell duration model framework with time-varying covariates. 6

Although most smallholders in the study areas report adopting snowpeas at some point in time, significantly fewer smallholders were still growing the crop in 2005, and of these only a very small share has grown the crop since the early 1980 s. The vast majority dropped out in the 1990s, a period of particularly adverse conditions due to, as mentioned earlier, a combination of agronomic and market factors. In this paper, although we also model the pre-adoption spell, i.e. the number of years it took a household to first adopt snowpea cultivation, we are particularly interested in evaluating the sustainability of NTX adoption and identifying those factors driving withdrawal from NTX production. Particularly, we are interested in ascertaining the role played by changes in the global market and the institutions that facilitated access to that market. In view of the dramatic changes in profitability of NTXs over time and the withdrawal from NTX production observed in the study area, the core hypothesis we will explore is whether in the face of increasingly difficult global market conditions only betterendowed farmers, particularly in terms of land and labour, were able to successfully continue cultivating NTXs. Conversely, it may be the case that other factors, namely institutions and policy interventions, were able to mitigate adverse conditions that unraveled over time, allowing poorer farmers to continue in the production of NTXs and

3 The maximum number of years producing snowpeas is 26, for households that started in 1980 and were still producing as of the 2005 survey.

41 cuerda $=0.11$ hectare.

5 For a review, see Feder et al. (1985) or Feder and Umali (1993). See also von Braun et al. (1989) and Katz (1992) for application to NTX adoption in Guatemala.

6 Although the use of duration models had its origin in biomedical research, this estimation technique has been increasingly applied to a variety of issues in economics, including technology adoption, unemployment spells and even participation in social assistance programmes. For a review of empirical application of duration models in social sciences see Kiefer (1988) and Lancaster (1990). 
take advantage of globalization. Whichever the case, we then explore how the timing of NTX adoption and the duration of cultivation actually may have translated into welfare improvement among the poor in the long run. Examining the determinants and impacts of snowpeas adoption and withdrawal, the paper therefore provides insight into how increased smallholders' export orientation can influence the livelihoods and welfare of the rural poor, and whether actions ought to be taken to facilitate access to global markets.

The remainder of the paper is organized as follows. Section 2 provides the conceptual foundations of the paper, noting the general approach taken and the factors that are believed to influence adoption of NTXs as well as withdrawal from cultivation. The data used for the analysis are described in Section 3, together with a brief description of the patterns of adoption/withdrawal and the main variables used in the analysis. Section 4 provides an explanation of the empirical approach used to analyse adoption and withdrawal and presents the results of the econometric analysis. Section 5 relates adoption and withdrawal to long term changes in welfare. Conclusions and policy implications are then presented in Section 6.

\section{Characterizing NTX adoption and withdrawal}

As mentioned, the empirical literature on adoption can be schematically divided into two separate strands. On the one hand, various studies have analysed the decision to adopt based on the simplifying dichotomy adopters vis-à-vis non-adopters (Waktola 1980; Kebede et al. 1990; Yirga et al. 1996; Dadi et al. 2001), mostly by estimating limited dependent variables models such as Probit or Tobit. On the other hand, a number of studies (Carletto et al. 1999; Baltenweck 2000; Fuglie and Kascak 2001; Burton et al. 2003; and Dadi et al. 2004) have specified the adoption decision within a duration model framework, to account for the dynamic nature of adoption and the effect of time-varying factors, while also adequately capturing the diffusion of the technology over time. The former approach can be quite restrictive and potentially misleading7 given the dramatic transformation of cropping patterns observed over the past two decades in the area under study. We thus take the latter approach.

In fact, in the presence of the volatile and ever changing conditions that have characterized NTX production and marketing in the highlands of Guatemala over the past quarter century, framing the problem within a multi decisional context is far more appealing, and likely to produce more relevant results. We analyse farmers' repeated decisions to adopt and/or withdraw from NTXs within a hazard model framework in which the spell of NTX adoption - as well as the spell of foregone adoption - will be analysed in relation to a number of time-variant (and invariant) covariates in order to shed light on the dynamics of export crop adoption, its sustainability for smallholders, and the efficacy of policy interventions in sustaining commercialization among smallholders.

Specifically, we first model farmers' decision to adopt snowpeas at some point after 1979, where the spell is identified as the number of years between the first year of the

7 For further evidence, see Mohr (1982). 
farmers' exposure to the 'risk of adoption' and the actual adoption. 8 In some cases, households had not yet adopted at the time of the survey even after being 'at risk' of adoption for over twenty years. In duration modelling, these cases are treated as rightcensored, meaning that real time at risk continues even though the observation period has ended, as it is plausible that they may end the spell by adopting at some unobserved future date. 9 Similarly, for NTX adopters only, we also model the subsequent decision to withdraw from growing NTXs, where the spell indicates the number of years of continuous adoption. 10 As several smallholders have not yet stopped cultivation of NTX but they may elect to do so in the future, the spell will also be treated as censored.

Following Carletto et al. (1999), NTXs are assumed to be more labour intensive and riskier than traditional crops and involve higher entry costs. Each year a farmer who has the option to adopt will decide whether to allocate land to NTX production based on the expected change in utility following adoption. Once adoption has occurred, the farmer must decide whether to continue to produce the crop or to withdraw from production based on whether the benefits from continued production outweigh the costs. As both household and external factors change, farmers may alter their inter-temporal decision to adopt or withdraw. Within this framework, a number of testable hypotheses can be derived in terms of factors driving the adoption and withdrawal process. These are explored below. For each factor the adoption and withdrawal decisions are considered.

\subsection{Prices}

While market conditions for producing snowpeas were especially favourable in the early 1980s when the majority of farmers adopted, prices steadily declined and became more volatile in the 1990 s, increasing risk and decreasing profitability. Changes in the price of snowpeas mirrored other exported vegetables and reflected changes in the global market. For green peas (snowpeas as one of the major green peas), the total value of exports from Central American and the Caribbean went from US\$1.5 million in 1992 to 19.1 million, and Guatemala went from less than US\$1 million to US\$12.5 million, or one-quarter of world peas exports in 2001. As generally the case with vegetable exports in this period, volume increases exceeded value increases reflecting a decline in prices. For Central American and the Caribbean, volumes of green peas exported went from 4,500 tons in 1992 to 24,300 tons in 2001 and for Guatemala, over the same

8 The beginning of the spell is either 1979 or the year of household formation, whichever comes later. This is because for households which were not yet formed in 1979, their exposure time begins at household formation. However, as the 2005 survey is part of a panel from a 1985 survey, most households were already formed by 1979 .

9 Although nothing precludes farmers from adopting NTX at a later stage, it would be reasonable to assume that the probability of doing so after such a long spell is close to zero. As a possible extension of this analysis, a split model could be estimated to account for this fact.

10 In the vast majority of cases, farmers reported growing snowpeas annually, without interruptions. However, about one-sixth of snowpeas adopters stopped growing snowpeas for a period of at least three years and then started again, producing for at least another three years. This stage of the analysis treats only households' first adoption spells. In other words, once a household has adopted for at least three years and withdrawn from snowpeas production for at least three consecutive years, it is no longer considered at risk of adoption again. This three-year criterion was adopted to sift out occasional adopters, or households that temporarily interrupted production for a limited time. Subsequent stages of analysis could allow for multiple adoption spells. 
period, from less than 1,000 tons to 17,000 tons (FAO 2007). While output prices fell, input costs did not fall commensurately (Immink et al. 1995) and in most cases actually increased substantially. The assumption is that observing lower output prices will deter new entrants. In a similar fashion, higher expected prices are assumed to foster continued production of snowpeas, leading to higher risks of withdrawal as prices decline. The time-variant annual average price, lagged by one year (Price_avg), is included to capture this effect.

\subsection{Land}

Average land ownership in the study area is quite low, at 3.7 cuerdas per household in 1985 and 4.5 cuerdas in 2005 - corresponding to less than 0.1 hectare per capita, on average - while 21 per cent of households reported not owning any land. Over 40 per cent of all households in the sample rent small amounts of land (1.4 in 2005 cuerdas, on average). Average farm size11 in 2005 was around 5.3 cuerdas. Given the shortage of land, NTX cultivation was often practiced at the cost of reducing land allocation to traditional crops and/or decreasing or completely eliminating fallow time in each plot. However, despite ubiquitous land shortage, adoption was widespread, if quite limited in most cases in terms of extent.

Land ownership, by increasing access to credit and reducing risk aversion, would be expected to increase the probability of adoption. However, in view of the widespread adoption observed across all classes of smallholders, we hypothesize that land, at least initially when most adoption appear to have occurred, may have played a minor role in the decision.

The land variable is first introduced in the model as a time-invariant variable measuring farm size, or the total amount of land available for cultivation, either owned or through rental. However, only the 2005 value is available, leading to concerns that current land holdings reflect prior cultivation decisions. In the final model, we introduce, instead, a time-varying covariate reflecting total owned land (land_owned) in the previous year as a proxy for the amount of land available for cultivation. We believe that this latter variable may be more suitable for capturing the household's potential land constraint to adoption over time as it does not suffer from the same endogeneity problems likely to affect the 2005 farm size variable. 12

Furthermore, access to better quality land may have also contributed to the smallholder's decision to adopt. The concept of land quality can be expressed through a number of variables describing the suitability of the land for NTX production during those months with the lowest environmental and market related problems and thus of highest returns. While during the rainy season water is abundant, pest infestations, as well as the likelihood of cold weather and water damages to the crop, are highest.

11 Farm size was computed as owned land minus land rented/given out plus land rented in/received for cultivation.

12 Regrettably, with the data at hand, we were not able to reconstruct the farm size variable for each year as the survey asks about borrowed/rented land only for the agricultural season 2004-2005. This would have been preferable to the variables used, as it would have captured all land availability at the time of making the decision. 
Although pest problems - and thus input costs - are lowest during the dry season, when incidentally output prices are also higher, water shortage is likely to constrain cultivation. For this reason, availability of flat/low erosion land - which tends to retain both soil and moisture, thus allowing increased production during the dry season emerges as a potentially important factor in the farmer's decision to adopt. To capture the concept of land quality we use an index variable (land_qual) that incorporates slope, level of erosion and irrigation for the best plot of land owned by a household. 13

For withdrawal, land factors are also expected to play a key role in the sustainability of NTX production. Land may impact farmer decisions in at least two ways. Amount of land determines ability to rotate crops in a way that reduces soil depletion and maintains higher yields. Equally, the quality of land continues to play a critical role after the initial adoption decision. This effect may be even more important if low erosion and high humidity or irrigated land is better suited to weathering the harsh conditions imposed by snowpeas cultivation.

\subsection{Labour}

Snowpeas are considerably more labour intensive than traditional crops. Furthermore, because of high supervision requirements, snowpeas production is characterized by sizable moral hazard problems that, together with pervasive liquidity and credit constraints at the household level, make hired labour an imperfect substitute for family labour. Consequently, family labour availability is expected to foster adoption and is captured by a time-variant variable reflecting the number of adult household members 14 each year of potential adoption (adults). Similarly, it is expected that households with more adult members have an advantage in sustaining snowpeas production over time thus delaying the decision to withdraw.

\subsection{Household characteristics}

The age of the household head (age), as well as the head's education (education) are included in the both models. Younger people, exhibiting a lower risk aversion and being at an earlier stage of a life cycle, are more likely to adopt riskier non-traditional cash crops. Also, more educated farmers are hypothesized to have better chances with agronomically complex cultivations such as snowpeas (Rahm and Huffman 1984; Kebede et al. 1990; Asfaw and Admassie 2004).

However, while age may deter households from adopting for reasons of risk aversion, once a household adopts, age may foster longer snowpeas production, through increased prior experience or more selective market entrance; alternatively, age may be associated with declining health, which would likely encourage withdrawal (Rahm and Huffman 1984). Furthermore, given that education is expected to allow households to obtain better information and use it more effectively, it is likely to enable them to make better

13 The 'best' plot of land is the one with the highest index score. This measure is used instead of average land quality because generally only a portion of land holdings is devoted to snowpeas cultivation and thus not all land would have to be suitable for snowpeas for a household to grow the crop.

14 'Adult' here includes household members ages 15-55. 
decisions. The effect of education on withdrawal may depend greatly on circumstances, and thus its effect is ambiguous; more educated farmers may be the quickest to withdraw if events merit such a move but also more capable of maintaining production in the face of adversity.

\subsection{Assets}

Both agricultural and non-agricultural assets are expected to promote adoption of more capital intensive NTX crops by improving household access to credit and reducing the households' degree of risk aversion. We test the hypothesis by including two timevarying variables: (a) an index indicating the level of durable asset ownership in 1985, 1995 and 2005 (durables); 15 and (b) a similar index for agricultural assets in the same years (ag_assets). The values are converted into a step-wise time-variant function, with the 1985 value used for the 1980 s, the 1995 for the 1990 s and the 2005 for each of the five years preceding the survey.

Since agricultural assets may both increase access to credit and improve agricultural productivity, withdrawal is less likely for households endowed with such assets. An accumulation of such assets may also offer an indication of a household's commitment to agriculture, as well as previous experience and success. Higher values of nonagricultural durable goods may also facilitate access to credit and reduce risk aversion, but may also proxy for increased ability to diversify out of growing snowpeas when problems arise.

\subsection{Time}

Time enters the hazard model in a number of ways. In addition to capturing changing conditions through some of the above covariates expressed in time-varying form, different specifications of time, both at the household and community level, are also introduced in the model.

\subsubsection{Household time}

In modelling a duration spell, we are in essence tracking each 'household time', which corresponds to an idiosyncratic 'calendar time' for each household, depending on the year of first exposure to the possibility of adopting snowpeas or withdrawing after adoption. Household time is inherently embedded in the model as the $t$ used to describe the hazard functions underlying the duration modelling, allowing that the simple passage of time once 'exposed' may affect a household's probability of making the decision of interest. This effect may increase the probability of adoption as a result of learning-from-others or other unobserved characteristics, or it may decrease it following the cumulative effect of factors like increased toxicity and soil depletion. For withdrawal, the passage of time following adoption may again work against a household, if the production is not environmentally sustainable or, conversely, if each

15 The weighted indices were computed using principal component analysis, based on pooled information for 15 durable items (and 15 types of agricultural equipment and tools) for each of the available years (1985, 1995, and 2005). 
additional year the household 'survives' in the market reflects its greater suitability for snowpeas production.

\subsubsection{Origin of spell}

Again, a spell begins only once a household is 'at risk' of the event - adoption or withdrawal - occurring. In the case of adoption, we first control for the household idiosyncratic beginning of the spell (start_a): for most households, this corresponds to 1980 , the first possible year of adoption when snowpeas cultivation was introduced to the region. For a few households that were not yet formed in 1980, exposure to NTX only started later on, at the year of household formation. Under the assumption that some 'learning from others' is at work despite deteriorating conditions, latecomers may have been in a better position to adopt, at least in the first decade of possible adoption.

Similarly, in the withdrawal model we control for the year of adoption (start_w), which demarcates the beginning of the withdrawal spell for each household. On the one hand, with time, farmers are assumed to accumulate knowledge about NTX production and marketing. Thus, early adopters could be at an advantage, benefiting from longer experience, particularly in the early, more profitable years. On the other hand, factors like accumulated toxicity and soil depletion may put early adopters at a disadvantage (Thrupp et al. 1995). Furthermore, late adopters may also be expected to withdraw more easily if their late entrance reflects that they were less suited to snowpeas cultivation in the first place.

\subsubsection{Markets and institutions}

As mentioned, starting in the early 1990s, the marketing of snowpeas has been fraught with frequent problems, primarily due to import bans imposed by customs authorities in the USA following the detection of unauthorized pesticide residues (Carletto et al. 1999). This period of deteriorating market conditions coincided with a period of increasing management problems at the cooperative, which, at least initially, had been a source of credit, inputs, technical assistance and export access for a growing number of community members. Mounting financial problems seriously inhibited the cooperative's ability to support its members for much of the 1990s. Following a management overhaul at the cooperative in the early 2000 s, most of the services to its now much restricted number of members have been re-established, thus potentially creating the conditions for a reversal in trend. To capture the dynamics of these changing conditions in both marketing and institutional conditions, we introduce two time-varying dummy variables for the period 1990-2001 (epoch_90-01) and 2002-2005 (epoch_02-05), corresponding to the two major shifts in cooperative management, also corresponding to changing market conditions.

\subsubsection{Village experience}

Following Carletto et al. (1999), we also introduce a variable (Village_t ) reflecting the cumulative effect of village level adoption. This time-variant variable is computed as the share of villagers who grew snowpeas the year prior to the farmer's decision to adopt. The effect of the diffusion of snowpeas among fellow villagers on the household decision to adopt is ambiguous: on the one hand, there are possible economies of scale in transport and economies of scope in the diffusion of information that may increase the propensity to adopt. On the other hand, factors like growing competition, crowding 
out of new adopters and increasing land prices as a result of the adoption of more profitable crops may have an increasingly negative impact on adoption. Over time, this negative impact is expected to become the more influential force, pushing producers to withdraw through competition for markets and resources, as well as reducing productivity as intense cultivation with fertilizers and pesticides leads to toxic buildup in the soil.

\subsection{Village fixed effects}

Finally, we include controls for village fixed effects. While the diffusion of NTX cultivation at the village level is already included, the fixed effects are expected to capture other differences by location, including distance, local infrastructures, as well as the fact that snowpeas were not uniformly introduced to all communities at the same time.

\section{Data and descriptive stats}

This study is based on data collected in the spring of 2005 in six communities in the Central Highlands of Guatemala served by the Cuatro Pinos cooperative. 16 The survey design entailed re-interviewing, after a 20-year span, the original households of a survey carried out in 1985 (von Braun et al. 1989). 17 Prior to the 2005 survey, extensive fieldwork was carried out in the fall of 2004 to locate the original sample of households and create a comprehensive list of the names and whereabouts of each original household member for a follow-up interview.

Out of the initial 1985 sample of 399 households, a total of 324 households could be identified and located in the course of the listing operation. The total sample for this study includes 296 households. 18 Full histories of NTX adoption and membership in the cooperative were collected, together with detailed information on the socio-economic situation of the households. Recall methods were also used capture trends in asset positions, as well as to collect full land transaction histories.

16 The six communities are Santiago Sacatepéquez, Pachalí, San José Pacúl, Santa Maria Cauqué, San Mateo Milpas Altas and El Rejón. The cooperative is located in Santiago Sacatepéquez.

17 For details on the original sample design, see von Braun et al. (1989).

18 Of the original 399 households, neither the name of the household head nor address information were available for about 20 cases, thus we had to exclude these households from the listing operation, bringing down the number of potential panel households to about 380 . In approximately 50 cases, only households of the children who had left the original households were available, and in a few cases, the male heads of original households appeared to have changed. Only the original households with original male heads are used for this study. Further data cleaning eliminated households with insufficient or suspect information, yielding a final adoption sample size of 296. The sample used for withdrawal totals 242 and excludes one household that adopts in the final year of observation, as the model does not allow for adoption and withdrawal within the same period. 
As mentioned, more than 20 years from the onset of the NTX boom in the area, the agricultural configuration and socio-economic make-up of the communities appear to have changed quite dramatically. Many farmers have succeeded in continuing to grow NTXs, but many more have abandoned cultivation. Others have entered production significantly later, with mixed success. Figure 1a shows the survivor function for the NTX adoption decision. The survivor function indicates the probability for a unit to survive beyond some time $t$ or, in other words, the share of households that still have not adopted at a given time $t$. Most farmers in the sample adopt snowpeas (82 per cent), 19 and the vast majority of these adopt within the first few years of exposure, partly thanks to the incentives provided through a vibrant cooperative in terms of inputs, technical assistance and market support. By 1985, 65 per cent of the sample, or 80 per cent of ever-adopters, had already adopted. However, as can be seen in Figure $1 \mathrm{~b}$ which presents the survivor function for the withdrawal decision - i.e. the percentage of adopters who have not withdrawn - the first signs of desertion started almost immediately, indicating that for a number of farmers NTX adoption was short lived. From time of adoption until 2005, only one-quarter of adopters produced snowpeas uninterruptedly. 20 Two additional features emerging from the figures are noteworthy: in the adoption process, virtually no new adoption is observed after 1995; and the withdrawal survivor function depicts a gradual but persistent withdrawal process, with generally higher rates from the late 1980 s on. 21

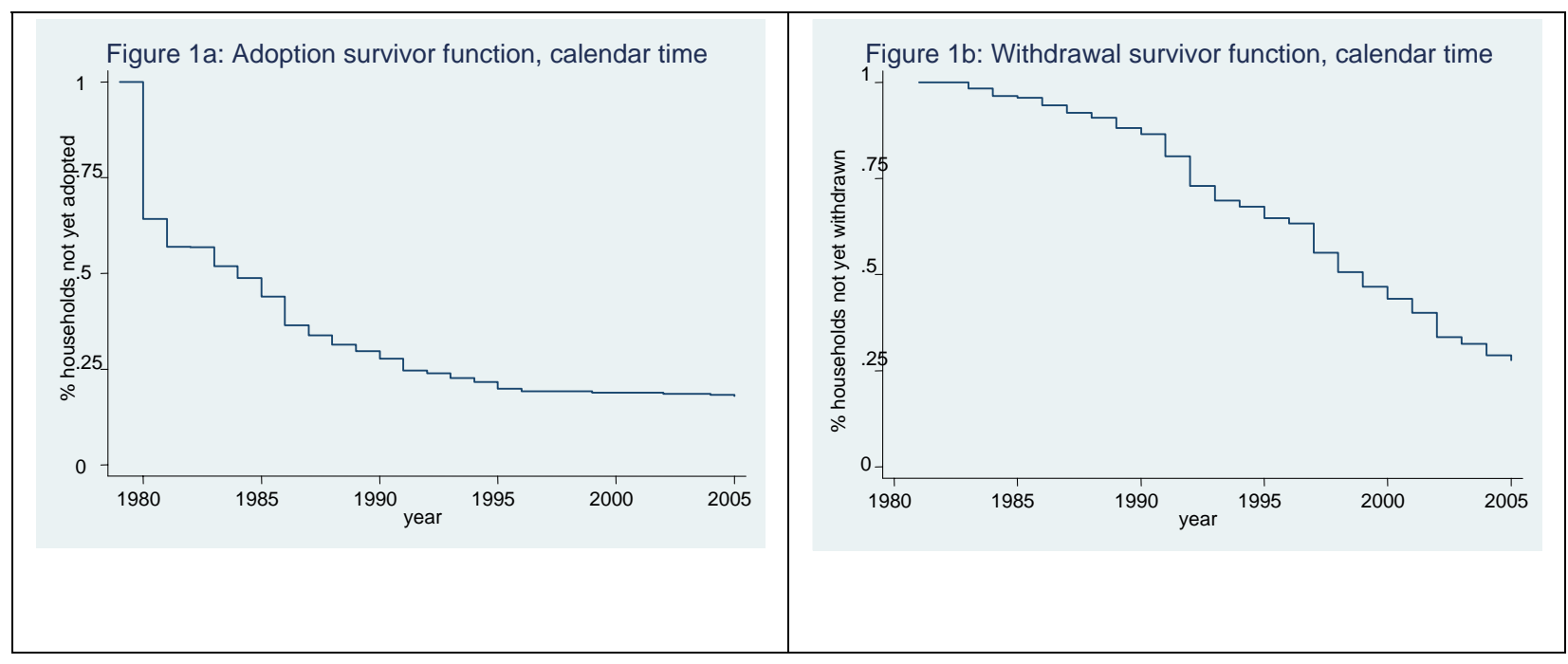

19 This percentage rises to 85 per cent when 'incidental adopters'who adopted for two years or less are included.

20 Here and in the subsequent analysis, 'uninterrupted' is defined as not having stopped producing snowpeas for more than 2 years. Thus, in calculating the spell in the withdrawal model, a household is assumed to change state, i.e. withdraw, only when stopped producing for more than 2 years.

21 Exceptions are the 1991-1992, 1996-1997, and (to a lesser extent) 2001-2002 seasons, in which more pronounced drops in survival are detected, likely because of some 'heaping' effects due to recall bias. 


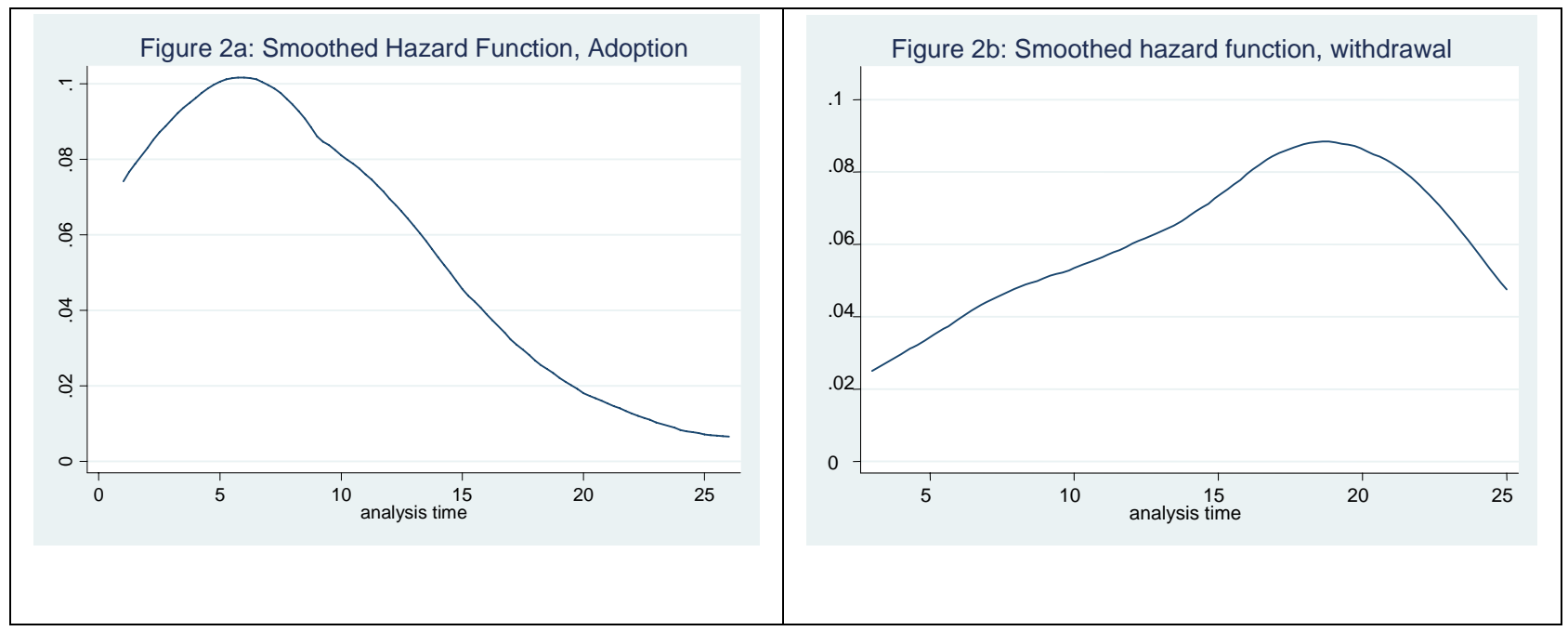

Figures $2 \mathrm{a}$ and $2 \mathrm{~b}$ present the events from a slightly different angle. While the above survival functions show the percent of the population that has yet to undergo the event of interest (adoption, or withdrawal among the sample of adopters), these empirical hazard functions give the likelihood of adopting (withdrawing) in each time period (starting from the first year 'at risk' of adoption or withdrawal) 22 conditional on not having adopted (withdrawn) by the previous time period. The hazard functions suggest an initial acceleration of adoption and then a strong and consistent downward trend in adoption, showing that if farmers did not adopt early, they became less and less likely to do so in the years ahead. The withdrawal hazard function in Figure $2 b$, on the other hand, suggests slow but growing pressure to withdraw peaking at about 20 years after initial adoption.

Table 1 compares the characteristics of adopter households and non-adopters. 23 Looking at land assets, with an average of 2.4 cuerdas per household, adopters had approximately one cuerda more than non-adopters at the time of first possible adoption. In terms of land quality - as captured by the share of land without erosion problems adopters and non-adopters were not significantly different at the beginning of their preadoption spell. By 2005, however, the land gap between adopters and non-adopters had widened: 83 per cent of adopters reported owning land, compared to 67 per cent of nonadopters. Adopters' owned land had doubled to an average of just over five cuerdas, while non-adopters still owned just 2.2 cuerdas on average. The difference in terms of farm size is even larger, with adopters controlling about 6 cuerdas of land for cultivation.24 Adopters' land was also more likely to be irrigated (though the percentages are low for both groups) and less likely to suffer erosion problems.

22 Note again that while 'calendar time' is the same for all households, 'household time' is not.

23 In the table, 'incidental adopters' who grew snowpeas for two years or less are classified as nonadopters.

24 The trend seems to suggest differentiated land accumulation patterns across smallholders driven by adoption. Although we are aware of the problem, for the time being we are treating the land variable in the duration model as exogenous. 
Table 1 Selected descriptive statistics for adopters and non-adopters

\begin{tabular}{|c|c|c|c|c|c|}
\hline & $\begin{array}{c}\text { Full } \\
\text { sample }\end{array}$ & Adopters $^{b}$ & $\begin{array}{l}\text { Non- } \\
\text { adopters }\end{array}$ & Difference & |t-stat| \\
\hline Number of observations & 296 & 243 & 53 & 188 & \\
\hline \multicolumn{6}{|l|}{ Land assets } \\
\hline $\begin{array}{l}\text { Total land owned (cuerdas), beginning of pre- } \\
\text { adoption spell }\end{array}$ & 2.22 & 2.40 & 1.44 & 0.96 & 1.49 \\
\hline $\begin{array}{l}\text { Per cent of households that report owning land, } \\
2005\end{array}$ & 80.0 & 83. & 66.7 & 16.4 & $2.75^{\star \star \star}$ \\
\hline Total land owned (cuerdas), 2005 & 4.54 & 5.07 & 2.19 & 2.88 & $3.72^{\star \star \star}$ \\
\hline Total farm size (cuerdas), 2005 & 5.34 & 5.95 & 2.55 & 3.40 & $4.34^{\star \star *}$ \\
\hline Low erosion land, per cent of total, 2005 & 70.0 & 71.7 & 62.2 & 9.5 & 1.44 \\
\hline Irrigated land, per cent of total, 2005 & 8.8 & 10.2 & 2.5 & 7.7 & $2.21^{\star \star *}$ \\
\hline $\begin{array}{l}\text { Quality score of best plot, beginning of pre- } \\
\text { adoption spell }\end{array}$ & 2.63 & 2.74 & 2.12 & 0.62 & $2.38^{\star * *}$ \\
\hline Quality score of best plot, 2005 & 3.30 & 3.31 & 3.21 & 0.10 & 0.49 \\
\hline \multicolumn{6}{|l|}{ Human capital assets } \\
\hline Year of household formation & 1970 & 1970 & 1969 & 1 & 0.79 \\
\hline Household size, beginning of pre-adoption spell & 5.38 & 5.35 & 5.52 & -0.18 & 0.49 \\
\hline Average household size, 2005 & 6.15 & 6.26 & 5.64 & 0.61 & 1.45 \\
\hline $\begin{array}{l}\text { Adults in the household, beginning of pre- } \\
\text { adoption spell }\end{array}$ & 2.45 & 2.43 & 2.53 & -0.10 & 0.59 \\
\hline Average household adults, 2005 & 4.18 & 4.31 & 3.57 & 0.75 & $2.36^{\star *}$ \\
\hline $\begin{array}{l}\text { Age of household head, beginning of pre- } \\
\text { adoption spell }\end{array}$ & 31.7 & 31.1 & 34.5 & -3.50 & $2.40^{\star \star \star *}$ \\
\hline $\begin{array}{l}\text { Average final school grade completed by head of } \\
\text { household }\end{array}$ & 2.6 & 2.70 & 2.17 & 0.53 & 1.60 \\
\hline
\end{tabular}

Notes: $\quad{ }^{a}$ Beginning of pre-adoption spell is 1980, or year of household formation for households that were formed between 1980 and 1985.

${ }^{\mathrm{b}}$ Adopters are those households that cultivated snowpeas for more than two years.

${ }^{* \star *}$ denotes significance at the $1 \%$ level; ${ }^{* *}$ at $5 \%$, and ${ }^{*}$ at $10 \%$.

Households do not appear to differ in terms of year of formation and availability of household labour. The heads of adopting households were significantly younger, though, at 31 years versus 34.5 years among non-adopters. They had also completed more years of schooling.

Finally, in Figure 3 we show the declining price trend of snowpeas for the period 19792005. Average prices were constructed using data from daily/weekly port prices for Miami - a primary destination for Guatemalan snowpeas - collected by the US Department of Agriculture. Yearly averages were derived from the average of the high and low price each week. 25 The original data were reported as US\$, which were then

25 Snowpeas price data were only available starting in the late months of 1987, so the 1987-2005 prices were used to predict the earlier prices back to 1978. The prices were first predicted in US\$ and then adjusted for exchange rate and inflation, yielding results consistent with anecdotal evidence of 
converted into real Quetzales per pound (indexed to year 2000) using the exchange rates and Consumer Price Index from the IMF's International Financial Statistics Yearbook (2005). The graph shows that with the exception of a stable period in the late 1980s, the price of snowpeas has continuously fallen, partly reflecting the expansion in the global supply in the market. The declining price is likely to influence both adoption and withdrawal.

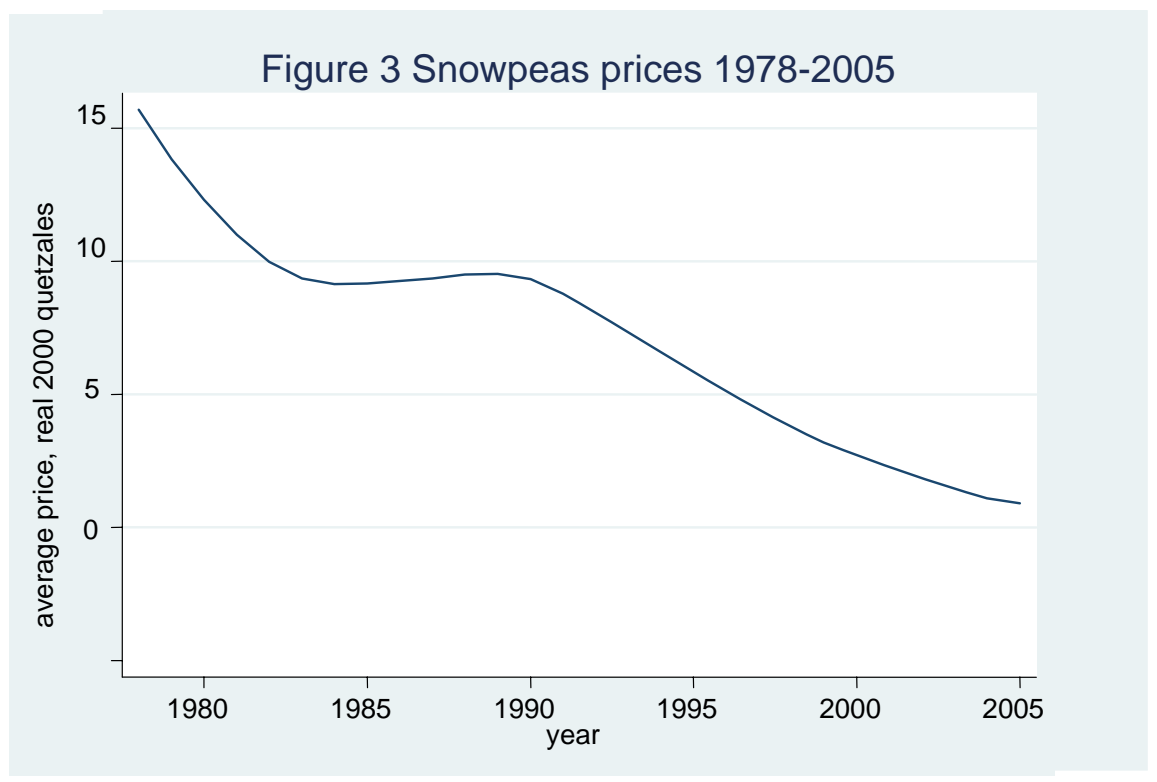

\section{Understanding NTX adoption and withdrawal}

\subsection{Empirical specification}

Duration modelling allows for the analysis of the decision over time to adopt and withdraw from the cultivation of snowpeas. 'Risk' of adoption (and withdrawal) over time can expressed through the hazard rate

$$
h(t)=h_{0}(t) e^{\left(\beta^{\prime} x\right)}
$$

indicating the probability of adoption in any given time period $t$, conditional on not having adopted up through time $t$-1. Including the distribution of the hazard rate $h_{0}(t)$ allows us to control for trends in 'household time' $t$, as we estimate the effect of other household and external factors. The term $e^{\left(\beta^{\prime} x\right)}$ incorporates the multiplicative effects of the vector of covariates on the hazard rate, including $e^{\left(\beta_{0}\right)}$ for an estimated intercept $\beta_{0}$, which can be multiplied by the hazard distribution $\mathrm{h}_{0}(t)$ to get the 'baseline hazard function'. This baseline hazard is interpreted as the likelihood of the event of interest

especially high prices as Guatemalans first entered the market, followed by high prices in the 1980s and declining prices in the 1990s. 
occurring in time $t$ if all other covariates were valued at zero. In the above form, the model is referred to as a proportional hazards model.

Duration models can be estimated using both parametric and non-parametric methods for specifying the hazard rate. If assumptions regarding the underlying functional form of the hazard function can be made with some confidence, parametric models are generally preferred since they provide for a clear pattern of survival. However, the choice of the proper functional form is not straightforward and several diagnostic tools are proposed in the literature. For the present study, and consistent with common practice, the Weibull distribution was chosen, 26 for which the hazard function can be expressed as

$$
h(t)=\lambda(x)^{\rho} \rho t^{\rho-1}
$$

where

$$
\lambda(x)=e^{-\beta^{\prime} x}
$$

is the scale parameter, which is a function of the vector of covariates $\mathrm{x}$, and $\rho$ is the shape parameter, capturing the monotonic time dependency of the phenomenon at hand. In the case of time-varying covariates, also the scale parameter $\lambda$ will depend on $t$, as we substitute in the formula above $x$ with $x(t)$.

When the shape parameter $\rho>1$, the hazard function is monotonically increasing, i.e. the probability of changing state increases over time. Conversely, this probability monotonically decreases when $\rho<1$. In the unique case that the shape parameter equals 1 , there is assumed to be no time dependency and the Weibull reduces to the Exponential case.

For more intuitively-interpretable results, the above hazard rate can be parameterized into what is known as the accelerated failure time (AFT) model, a simple transformation of the proportional hazards model, which is what we use. In vector form, the AFT model can be expressed as

$$
\log (t)=\beta^{\prime} X+\sigma \varepsilon
$$

where $t$ is a non-negative random variable denoting adoption (withdrawal) time, $X$ is the vector of explanatory variables, and $\beta$ is the vector of corresponding coefficients. In the case of a Weibull hazard function, $\varepsilon$ is the error term that follows an Extreme value distribution, 27 scaled by $\sigma$, where $\sigma=1 / \rho$ is the inverse of the shape parameter. Unlike the proportional hazards form, which reports variables' effect on the hazard rate, the AFT coefficients can be easily interpreted as in regular regression models and reflect the acceleration or deceleration effect on the time until the occurrence of the event of interest (adoption or withdrawal).

26 Other functional forms, including the log-logistic, as well as the Cox semi-parametric method, were also estimated with somewhat mixed success. Further diagnostic is underway to fully ascertain the robustness of the results to different specifications.

27 Given an error term $\eta$ following a Weibull distribution, then $\varepsilon=\ln (\eta)$ has an Extreme value distribution. 


\subsection{Results}

\subsubsection{Adoption}

Table 2 shows the estimation results for the adoption decision, which are given in terms of AFT coefficients. A negative coefficient reflects a shorter pre-adoption spell (higher probability of adoption), while a positive coefficient indicates slower adoption (a longer pre-adoption spell). Consistent with earlier findings that snowpeas adoption did not discriminate against small landholders, possibly because of family labour advantages,

Table 2 Maximum likelihood NTX-adoption duration models, hazard functions

\begin{tabular}{|c|c|c|}
\hline Weibull distribution, 296 observations & Coefficient & (z-score) \\
\hline \multicolumn{3}{|l|}{ Household characteristics } \\
\hline \multicolumn{3}{|l|}{ Land assets } \\
\hline Land ownership, in cuerdas (land_owned) & -0.009 & $(-0.84)$ \\
\hline Land ownership, squared & -0.000 & $(-0.63)$ \\
\hline Quality of best plot (land_qual) & -0.008 & $(-0.64)$ \\
\hline \multicolumn{3}{|l|}{ Human capital assets } \\
\hline Age of household head (age) & $0.011^{*}$ & (3.68) \\
\hline Education of the head of household (education) & $0.051^{*}$ & $(2.18)$ \\
\hline Education of the head of household, squared & $-0.006^{\star}$ & $(-2.08)$ \\
\hline Number of household adults (adults) & 0.006 & $(0.31)$ \\
\hline \multicolumn{3}{|l|}{ Other assets } \\
\hline Agricultural assets: index (ag_assets) & $-0.098^{*}$ & $(-5.44)$ \\
\hline Durable goods: index (durables) & -0.026 & $(-1.08)$ \\
\hline \multicolumn{3}{|l|}{ Market conditions } \\
\hline Average prices, 2000 quetzals/lb (Price_ave) & $-0.104^{*}$ & $(-9.62)$ \\
\hline \multicolumn{3}{|l|}{ Role of time in adoption } \\
\hline Historical time: origin of adoption spell (start_a) & $-0.121^{*}$ & $(-4.16)$ \\
\hline \multicolumn{3}{|l|}{ Historical time: adoption epoch dummy: 1990-2001 } \\
\hline (epoch_90-01) & $0.633^{*}$ & $(7.03)$ \\
\hline \multicolumn{3}{|l|}{ Historical time: adoption epoch dummy: 2002-2005 } \\
\hline (epoch_02-05) & $1.202^{*}$ & $(4.68)$ \\
\hline Village time: $\%$ adopters in village (Village_t) & $0.021^{*}$ & $(16.24)$ \\
\hline \multicolumn{3}{|l|}{ Community fixed effects } \\
\hline San Mateo & $0.303^{*}$ & $(4.39)$ \\
\hline El Rejón & $0.460^{*}$ & $(6.11)$ \\
\hline Sta. Maria de Cauque & $-0.146^{*}$ & $(-2.55)$ \\
\hline Pacul & $-0.229^{*}$ & $(-2.70)$ \\
\hline Pachali & 0.107 & (1.39) \\
\hline Constant & $2.294^{*}$ & $(8.85)$ \\
\hline$\rho$ & 3.28 & \\
\hline$\sigma=1 / \rho$ & 0.305 & \\
\hline
\end{tabular}

Note: * coefficients significant at $95 \%$, or higher. 
the results indicate that amount of land owned at the time of adoption has not been an important factor in the decision process. Land quality is not significant either, suggesting that households were willing to try growing snowpeas without strongly considering the characteristics of the land. This may also be due to the fact that early on, no major pest problems were observed and chemical fertilizers and pesticides were more readily available and less expensive, thus reducing the need for cultivation on low erosion/high humidity land during the dry season.

Consistent with the hypotheses, the age of the head of household slows adoption while, contrary to expectation but in line with the cited study in the same communities (Carletto et al. 1999), family labour plays no significant role in the decision to adopt. This may reflect that fact that households would enter NTX production regardless of the amount of family labour available. However, labour supply is likely to have affected the extent of adoption, not captured by our model. The coefficients of the education of the household head, in quadratic form, are both significant, suggesting that higher education is associated with earlier adoption, but only above a threshold of about four years of schooling. Agricultural assets go hand in hand with more rapid adoption, while the effect of other non-agricultural durable assets is negligible. This seems to suggest that it is previous investment in agriculture that allows those to adopt more quickly and not overall wealth. This may also indicate that at least initially, when most adoption occurred, credit constraints - initially eased by the cooperative - played a more limited role in adoption as non-agricultural wealth, which should be linked to credit access, are less important.

A key finding of our estimation is the role played by (lagged) prices in the decision to adopt. Based on the estimation, farmers appear to be quite responsive to price changes, and households tend to adopt early on when prices were high and more stable. As prices fall over time, households who have not already started growing snowpeas become increasingly less likely to do so. Such a result highlights the fact that 'trade openness' may not be sufficient for moving poor households to actually participate in and benefit from global trade.

The year in which the household became first exposed to NTX production is important in the decision to adopt: households that formed later tend to have shorter pre-adoption spells. The result, however, could well be an artifact of the sample. Because our panel sample only includes households that formed up to 1985 - undoubtedly the most favourable years for snowpeas - it seems reasonable to assume that households forming after the introduction of snowpeas in 1979 , but prior to 1985 , might be more willing to enter the market quickly, having seen the techniques and benefits among those who had adopted previously. In the face of deteriorating conditions in the 1990s, households that formed after 1985, if present in the sample, would have found quick adoption less tempting.

Consistent with earlier results (Carletto et al. 1999), higher diffusion of snowpeas cultivation at the community level significantly predict lower adoption in the following year. It is not obvious, however, to what degree this may be attributed to a less-open market, soil depletion and toxicity, saturation of the pool of potential adopters, or caution acquired by learning from the failures of others.

As expected, the epoch dummies, introduced to capture changing market and institutional conditions after 1990, indicate that adoption became less and less likely 
over time: both are positive, with the latter period (2002-2005) characterized by even slower adoption than the former (1990-2001).

Also as expected, the community fixed-effects (with Santiago Sacatepéquez as the comparison group) also give significant results. Not surprisingly, El Rejón and San Mateo, the most distant and last-incorporated communities into the cooperative, were slower to adopt. There is also indication that households in Pachalí may have also been slower to adopt, while Pacúl and Santa Maria de Cauqué were generally faster.

Finally, the value of the shape parameter $\rho$ deserves some explanation. The estimated value is significantly greater than 1 , indicating, somewhat counter-intuitively, a strong positive time dependency in the probability of adoption. The parameter, however, seems to counterbalance the effect of the other time-dependent variables, all showing the opposite relation. In fact, as we run a different specification of the model without the other time variables, the shape parameter assumed a value smaller than 1, thus reflecting the overall negative time drift from the time-varying covariates.

\subsubsection{Withdrawal}

Table 3 presents the results of the withdrawal estimation. Again, negative coefficients for the AFT Weibull indicate a shorter expected time until withdrawal occurs (shorter duration of snowpeas production). Positive coefficients correspond to households producing the crop for longer periods of time.

For withdrawal, the amount of land owned remains insignificant, contrary to expectations, but higher quality of land significantly extends the length of the production spell. These findings suggest that land quality - having good land that can withstand intense use and allow cultivation in more propitious months of the year matters even more than land quantity to sustain NTX production over time.

While, as seen, older age decreased the likelihood of adoption, it does not lead to faster withdrawals. It seems that older farmers may be more risk-averse and not adopt, but those who do choose to enter are no less likely to stick with it. Having more household adults does not lead to longer NTX production. While agricultural assets slow withdrawal, durable non-agricultural assets are significantly associated with shorter adoption spells, possibly reflecting diversification away from producing snowpeas. Education of the household head is not significant; however, the sign and magnitudes of the coefficient suggest that there may be decreasing agricultural returns to education or that after a certain point, education may be better rewarded in other forms of work.

The year of snowpeas adoption is also a highly significant predictor of shorter duration of production. Late entrants are more likely to drop out sooner, probably as a result of not having been able to take full advantage of those early years of higher returns. Not surprisingly, average prices positively correlate to the adoption spell, with the trend of decreasing prices contributing to the growing abandonment of snowpeas.

Neither of the epoch dummies yields significant results. Village time - the lagged percentage of a household's community producing snowpeas - is significant, again indicating how a higher concentration of producers at the community level leads to faster withdrawal, possibly due to some combination of increased competition and pesticide resistance or toxicity build-up. 
Table 3 Maximum likelihood NTX-withdrawal duration models

\begin{tabular}{|c|c|c|}
\hline Weibull distribution, 242 observations & coefficient & (z-score) \\
\hline \multicolumn{3}{|l|}{ Household characteristics } \\
\hline \multicolumn{3}{|l|}{ Land assets } \\
\hline Land ownership, in cuerdas (land_owned) & 0.002 & $(0.14)$ \\
\hline Land ownership, squared & -0.000 & $(-0.00)$ \\
\hline Quality of best plot (land_qual) & $0.068^{*}$ & $(2.92)$ \\
\hline \multicolumn{3}{|l|}{ Human capital assets } \\
\hline Age of household head (age) & -0.002 & $(-0.05)$ \\
\hline Education of the head of household (education) & 0.043 & $(1.18)$ \\
\hline Education of the head of household, squared & -0.006 & $(-1.21)$ \\
\hline Number of household adults (adults) & 0.005 & $(0.26)$ \\
\hline \multicolumn{3}{|l|}{ Other assets } \\
\hline Agricultural assets: index (ag_assets) & $0.088^{*}$ & $(3.21)$ \\
\hline Durable goods: index (durables) & $-0.071^{*}$ & $(-3.21)$ \\
\hline \multicolumn{3}{|l|}{ Market conditions } \\
\hline Average prices (Price_ave) & $0.052^{*}$ & $(2.12)$ \\
\hline \multicolumn{3}{|l|}{ Role of time in withdrawal } \\
\hline \multicolumn{3}{|c|}{ Historical time: origin of withdrawal spell/time of adoption } \\
\hline \multicolumn{3}{|l|}{ Historical time: adoption epoch dummy: 1990-2001 } \\
\hline (epoch_90-01) & -0.025 & $(-0.19)$ \\
\hline \multicolumn{3}{|l|}{ Historical time: adoption epoch dummy: 2002-2005 } \\
\hline (epoch_02-05) & 0.133 & $(0.70)$ \\
\hline Village time: $\%$ adopters in the village (Village_t & $-0.019^{*}$ & $(-3.79)$ \\
\hline \multicolumn{3}{|l|}{ Community fixed effects } \\
\hline San Mateo & -0.122 & $(-1.09)$ \\
\hline El Rejon & $1.099^{*}$ & $(4.54)$ \\
\hline Sta. Maria de Cauque & 0.0578 & $(0.60)$ \\
\hline Pacul & $0.378^{*}$ & $(2.61)$ \\
\hline Pachali & 0.047 & $(0.40)$ \\
\hline Constant & $3.097^{*}$ & $(9.14)$ \\
\hline$\rho$ & 2.443 & \\
\hline$\sigma=1 / \rho$ & 0.409 & \\
\hline
\end{tabular}

Note: *coefficients are significant at $95 \%$, or higher.

Beyond the differences in the time-varying proportion of community producers, the coefficients on the community fixed effects make it clear that the snowpeas production experience has not been uniform among the six communities. Living in El Rejón, especially, corresponds to longer production spells. While El Rejón households did generally adopt later than the others, which otherwise predicts shorter withdrawal spells, it is known that El Rejón was the last to be allowed to join the cooperative. If this group's delayed adoption was geographically imposed rather than reflecting households' self-determined hesitation or poor suitability to grow NTXs, it seems likely 
that such a result reflects learning from others over time, or better overall environmental conditions. Similarly, Pacul also tends to exhibit slower withdrawal patterns.

Finally, the shape parameter $\rho$ is significantly greater than 1 , confirming that, even after controlling for all other time-varying covariates, the likelihood of withdrawal increases over time.

\section{The welfare impact of NTX adoption}

Thus far, the analysis has focused on examining which households are likely to adopt early on and sustain cultivation over time and how external factors such as global market changes and the performance of local institutions influence this choice. The next obvious step is to look into the degree to which NTX cultivation and export to the global market actually has been able to translate into higher incomes for adopters in the long run, particularly poor adopters, the primary rationale for introducing snowpeas in the first place. Early indications showed potential for pro-poor growth, justifying wider spread promotion of NTX crops (von Braun et al. 1989). However, the von Braun et al. study measured impacts after a relatively short exposure and, if returns have held after 20 years, it is expected that further accumulation of benefits will be found with longer exposure. A likely possibility, though, is that the previously mentioned challenges that have arisen since 1985, i.e. the time of the von Braun et al. study, have reduced the profitability of snowpeas over time. As already postulated, we also consider that adoption in the early years may have been different from adoption in later years, affected by global prices for snowpeas and their inputs, as well as more local factors such as community experience, crowding, and land depletion.

For descriptive purposes, we identify three types of households based on their adoption histories: (1) early adopters, who adopted by 1985, (2) late adopters, who adopted after 1985 but before 2005, and (3) non-adopters. A basic comparison of per capita consumption in 2005 of these three groups can be seen in Table 4 . The results seem to suggest that, overall, adopters in 2005 had consumption levels 14 per cent higher than non-adopters, though the difference was not significant. In terms of timing of adoption, we see that early adopters in 2005 were better off than late adopters, who in turn had higher consumption than those who had never adopted, though only the difference between the early and non-adopters was significant at the 95 per cent level.

Table 4 Per capita consumption in 2005

\begin{tabular}{ccccc}
\hline & Adopters & & Non-Adopters & Total \\
\hline Early & Late & Total & & \\
$5357^{*}$ & 5,022 & 5,215 & 4,582 & 5,105 \\
\hline
\end{tabular}

Note: *significantly different from non-adopters at the $95 \%$ level

This simple contrast, although informative, may be misleading. In fact, along with the complexity of considering different adoption spells over different periods, analysing the impact of snowpeas adoption on welfare is complicated by the fact that households that adopt have chosen to do so. It may be the case that households that adopt are fundamentally different from non-adopters and the differences in per capita 
consumption noted above reflect these differences and not the impact of adoption per se. Provided that adopting and non-adopting households have a similar range of characteristics, 28 it is possible to control for observable differences between households and attempt to identify impact through a regression framework that controls for observables. However, those that adopt and the spell for which they adopt may differ from other households in ways that are unobservable, a common problem when participation is due to self-selection. This self-selection into adoption means that any attempt at identifying impact is complicated by the fact that estimates may be biased by unobservable differences across households. Since those that do adopt and those that adopt early are more likely to be innovators, the expectation is that, if there is bias, it will overestimate the true impact of (early) adoption.

To overcome these difficulties and with the intent of reducing the bias in the estimates of the impact of snowpeas adoption on the welfare of these households, a number of steps are taken. First, we focus on the time to adoption and, given adoption, the time to withdrawal; this allows us to exploit greater heterogeneity across all households instead of just looking at adopters versus non-adopters. Adopters are thus compared to each other (but differentiated based on the timing and length of adoption) as well as to nonadopters. Second, we use predicted values of time-to-adoption and length of production: similar to an instrumental variables approach, predicted duration serves as the explanatory variable instead of actual duration to reduce bias that may occur when the factors that influence actual duration are correlated with consumption, our measure of welfare.

Thus, to quantify the impact of NTX adoption on household welfare, per capita consumption is first regressed on predicted time until adoption to examine the effect of timing of NTX production on long term welfare. The predicted years until adoption is included as a quadratic because of the earlier noted expectation that the influence of adoption is non-linear with earlier adopters benefiting more; controls are added for other observable household characteristics expected to impact welfare. As presented in Table 5, a large non-linear effect is found: the jointly significant coefficients of the time-toadoption variable suggest that households on the extremes - those with the earliest predicted adoption and those with the latest (e.g. likely those who would never adopt) 29 - are the ones relatively better off, supporting the idea that the biggest gains from snowpeas were to be achieved only through early adoption (or, by foregoing adoption altogether). 30

28 In the impact evaluation literature, this is referred to as having common support; namely, the fact that households that represent the counterfactual share the same range of characteristics and are thus a valid comparison group (Ravallion 2005) .

29 It must be noted that households with the longest pre-adoption spell include the censored observations in the duration model, i.e. the ones who have not yet adopted at the time of the survey.

30 The estimated U-shaped curve turns at about 5 years. 
Table 5 Impact of adoption on per capita consumption

\begin{tabular}{lcc}
\hline 232 observations & \multicolumn{2}{c}{ Years of cultivation } \\
\hline Time to adopt & $-1275^{\star}$ & -8.83 \\
Time to adopt, squared & 128 & 0.054 \\
Time to withdraw & & -45.3 \\
Time to withdraw, squared & & 140 \\
Household size & 87.5 & -6.77 \\
Head's education & -81.4 & 4.14 \\
Head's education, squared & 26.1 & 138 \\
Head's age & -19.4 & -2.291 \\
Period household formed & -38.7 & -14.71 \\
Period household formed, squared & 1.06 & -1.193 \\
Initial land & 106 & -104.8 \\
Initial land, squared & -7.58 & 2670 \\
Land quality & $-218^{\star}$ & \\
Constant & $7910^{\star}$ & \\
\hline
\end{tabular}

Note: * indicates significance at $95 \%$ or higher.

To contrast this finding to the results that would be obtained without using the predicted timing of adoption, in Figure 4 we map consumption either as a function of predicted time (estimated from the coefficients in the first column of Table 5) or actual time of adoption (estimated from a similar model as in Table 5). The comparison suggests that the actual time of adoption understates the impact of very early adoption but then overstates the benefits for much of the remaining time-to-adoption spell. That is, it appears that continued adoption, after the narrow early window of opportunity in the (early) 1980s, may have actually slowed adopters' trajectory of growth in the long run. This is most likely because non-adopters (and early adopters who later dropped out) may have found alternatives to snowpeas cultivation, such as non-farm employment, that limited the relative gains of late cultivation.

Figure 4 Impact of time until adoption on consumption in 2005

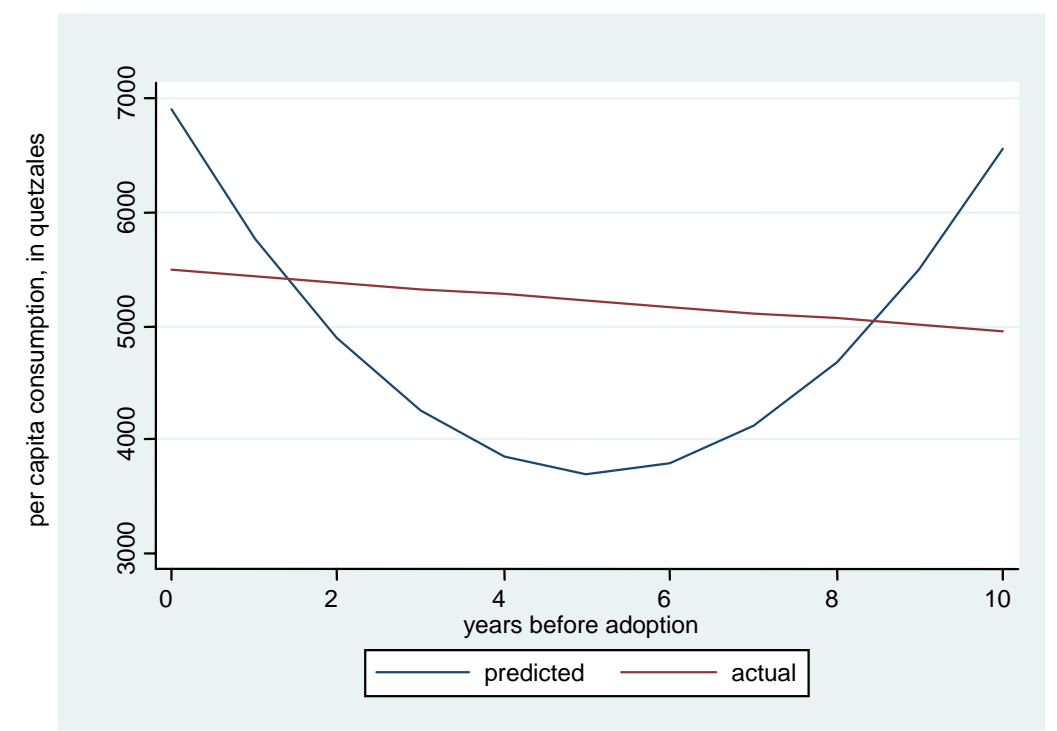


To look for any evidence of an accumulation of benefits related to longer periods of cultivation, per capita consumption in 2005 is then regressed on the predicted number of years of cultivation as estimated by the second duration model. 31 The predicted number of years is again specified as a quadratic to capture non-linearities, and observable household characteristics are controlled for. The results seen in the second column of Table 5 show that longer cultivation has no statistically significant impact on consumption. Thus it appears that households were no better off from cultivating snowpeas over the long run, at least before differentiating among households' timing of adoption, suggesting that any correlation seen between consumption and years of cultivation is likely to reflect the bias of pre-existing differences in welfare and/or different timing of adoption.

However, the timing of adoption and withdrawal are clearly related as those households that adopted earlier have had the opportunity to cultivate longer; thus, we combine both in a single regression (not shown). The results of this specification do not change and again point to the existence of a limited window of opportunity for getting the benefits of NTX production. As long as households began cultivating snowpeas early, there is little evidence to show that they benefited most by growing for longer periods of time, perhaps challenging the notion that households who ceased production in the 1990s were the most disadvantaged.

The story of an export crop presenting a prime window of opportunity, followed by the accumulation of adverse macroeconomic, agronomic, and institutional conditions would not be unique to snowpeas or Guatemala. The findings seem to provide evidence that NTX crops, as they tend to play out, may not always be a sustainable pathway out of poverty for the majority of households. However, by taking advantage of 'boom' periods, some (early) adopters may have been put in a more propitious position to later decide whether they will benefit most by continuing to cultivate or by using the gains from early, short term production as a stepping stone into other activities. In such a case, withdrawal from NTX production may not be a failure at all, and NTX adoption can be interpreted as a vehicle for greater, future opportunities.

\section{Conclusions}

More than twenty years after snowpeas were introduced to the central highlands of Guatemala to link farmers to global markets and foster rural development, this study has used duration analysis to explore how household characteristics and external trends play into both the adoption and diffusion processes of non-traditional crops among

31 The proper identification of both the adoption and withdrawal decisions is challenging, as most of the available variables believed to affect these decisions are also likely to be correlated with households' welfare levels. We select and test a number of variables assumed to have influenced the timing and length of NTX cultivation more directly than the household's consumption level, including the community of residence and concentration of snowpeas farmers in each community. These two variables can be assumed to have in part driven the adoption process - as NTXs were introduced in the communities at different times - and not be systematically correlated with welfare. For the withdrawal decision, we also use a variable capturing the degree of 'closeness' of the household to the cooperative. Presumably, better connected farmers may have been able to access for longer periods the services provided by a dwindling cooperative, thus potentially favouring prolonged adoption. 
smallholders, as well as how adoption may have translated into a reduction in poverty over time. Our re-examination of the NTX experience provides us with the opportunity to update earlier analyses based on a recent household survey conducted among smallholders in a selection of the communities that participated in the early NTX boom.

Adoption was widespread and rapid, which led the project to be hailed as a pro-poor success, reaching all but the smallest landholders. But constraints to sustained production have proven to be numerous, particularly in the second decade of the period considered; foremost among these constraints has been the deterioration of prices in global markets as new market entrants expanded supply and suppressed prices. Over time, more than two-thirds of adopters eventually dropped out, presumably reverting back to more traditional crops, or leaving agriculture altogether. While some challenges to sustainability (such as soil depletion and pesticide resistance) were noted earlier on, we exploit information for a period spanning across more than two decades to explore the long term sustainability of snowpeas production in the study area.

Consistent with previous findings, we find that smallholders are quite responsive to price incentives when repeatedly making their decision to adopt. As pointed out in Dadi et al. (2004) in their study in rural Ethiopia, if price incentives are strong enough, smallholders may be able to overcome possible deterrents to adoption, such as low education and risk aversion. The importance of improving marketing channels to enable farmers to fetch better and more stable prices, combined with the establishment of appropriate price information systems, emerges as a crucial policy message deriving from the results. Further, the centrality of prices for the success of continued NTX adoption raises a cautionary note on the viability of NTX promotion as a sustainable poverty alleviation strategy among poor, risk-averse small scale producers with limited capacity to weather volatile and/or declining prices. For communities such as these, increased trade in NTX stemming from openness to the global market may be an insufficient mechanism for achieving growth and poverty reduction if not conditioned on the presence of favourable relative prices.

Also in line with other empirical evidence, land size does not seem important in the decision to adopt: farmers seemed to adopt en masse, regardless of the amount of their land holdings. Presumably, the quantity of land may have influenced the extent of cultivation, and not whether a farmer would adopt. Similarly, but contrary to expectation, land size does not play an important role in delaying withdrawal. However, land quality emerges as a significant factor in prolonging production of snowpeas over time. As mentioned earlier, access to high humidity or irrigated land, allows production in those months in which prices are higher, production costs are lower, and the risk of crop loss are lowest. Given the pervasive scarcity of land that characterizes the area, and the observed agronomic problems deriving from the overuse of limited land resources, programmes promoting new cash crops in the area should also support micro irrigation and improved agronomic practices to enable production in more propitious times of the year.

In our duration models, time affects the decision and diffusion of adoption in a number of ways, and most seem to point to deteriorating conditions for NTX adoption. The combined effect of negative trends like toxicity build up, pest resistance, and timedependent prices and marketing outlets, all seem to suggest that snowpeas have become increasingly unpopular among smallholders in the study communities, who, since the early 1990s, have abandoned its cultivation in increasing numbers. Interestingly enough, 
a large number of new adopters from more distant regions of the country are replacing them in new production and commercialization schemes, including through the cooperative Cuatro Pinos.

Was rapid, indiscriminate diffusion behind a disappointing drop out rate? Going back to our core hypothesis, sustained NTX production does not appear to have been as propoor as initially hoped. Primarily better endowed farmers - in terms of good land and agricultural assets, though not labour - were able to overcome the increasingly adverse conditions. Institutions and policy interventions do not appear to have mitigated these difficulties in the favour of less endowed farmers, and the rush to join the snowpeas fad was followed by farmer after farmer ceasing production, often citing low prices, high input costs, debt, and an unreliable market as some of the chief culprits that ultimately pushed them out of NTX production.

It is not clear, however, that withdrawal should necessarily always be equated with failure. It does not appear that longer periods of cultivation have necessarily translated into higher consumption than shorter spells, so while falling profitability and high drop out rates may be disappointing, perhaps the possibility that households may have responded appropriately by shifting into other activities is less so. Timing rather than endurance emerges the more salient issue: early entrants seem to have fared better than their later counterparts perhaps, thanks to strong outside support, more quickly establishing themselves in the market and rapidly acquiring the technical know-how necessary for an agronomically difficult crop like snowpeas or simply taking advantage of boom prices to later diversify out of NTX production. In any case, preliminary results show early adoption to have led to higher long term consumption, while delayed adoption seems to have been worse, or not better, than not adopting at all, suggesting that the current strategy to expand the NTX frontier beyond the initial communities, while potentially profitable for the cooperative and for the country as a whole, may not represent a viable long term solution for poorer farmers unless the conditions to promptly diversity as soon as market and agronomic conditions start deteriorating are put in. Risk management support might make it easier for households to make timely and 'clean' exits and minimize the frequency of households being trapped into continued production because of debt or lack of know-how. For that to materialize, however, strong capacity must be built among farmers through unremitting institutional support. This, unfortunately, does not appear to have been the case in the study area past the 1980s.

This study highlights how the promise of globalization can fail to live up to expectations, at least for the poorest farmers. As shown, while poor farmers may be enticed into entering into NTX markets when conditions are favourable, they may lack the capacity to diversify or, conversely, to overcome difficulties that inevitably arise in complex types of cultivations and in highly variable global agricultural markets. While governmental and non-governmental organizations can attempt to mitigate these difficulties, market forces may overwhelm these efforts, with poorer adopters still unable to compete in the global markets. 


\section{References}

Asfaw, A. and A. Admassie (2004). 'The Role of Education on the Adoption of Chemical Fertiliser under Different Socioeconomic Environments in Ethiopia'. Agricultural Economics, 30: 215-228.

Baltenweck, I. (2000). 'Adoption of Grade Cattle Technology in Kenya: a combined Farm-level and Spatial Approach'. PhD dissertation, Université d'Auvergne, CERDI.

Barham, B., M. R. Carter, and W. Sigelko (1995). 'Agro-export Production and Peasant Land Access: Examining the Dynamic between Adoption and Accumulation'. Journal of Development Economics, 46(1): 85-107.

Burton, M., D. Rigby, and T. Young (2003). 'Modelling the Adoption of Organic Horticultural Technology in the UK Using Duration Analysis'. Australian Journal of Agricultural and Resource Economics, 47: 29-54.

Carletto, C., A. de Janvry, and E. Sadoulet (1999). 'Sustainability in the Diffusion of Innovation: Smallholder Non-Traditional Agro-Exports in Guatemala'. Economic Development and Cultural Change, 47 (2): 345-69.

Carletto, C. (2000). 'Non-Traditional Cash Crops and Land Accumulation among Guatemalan Smallholders: Is the Impact Sustainable?' FCND Discussion Paper 80. Washington, DC: IFPRI.

Dadi, L., M. Burton, and A. Ozanne (2001). 'Adoption and Intensity of Fertiliser and Herbicide Use in the Central Highlands of Ethiopia'. Agrekon, 40: 316-333.

- (2004). 'Duration Analysis of Technological Adoption in Ethiopian Agriculture'. Journal of Agricultural Economics, 55(3): 613-631.

FAO (Food and Agriculture Organization). 2007. 'TradeStat', available at http://faostat.fao.org/

Feder, G., R. E. Just, and D. Zilberman (1985). 'Adoption of Agricultural Innovation in Developing Countries: A Survey'. Economic Development and Cultural Change, 33: 255-298.

Feder, G. and D. Umali (1993). 'The Adoption of Agricultural Innovations: A Review'. Technological Forecasting and Social Change, 43: 215-239.

Fuglie, K.O. and C. A. Kascak (2001). 'Adoption and Diffusion of Natural-ResourceConserving Agricultural Technology'. Review of Agricultural Economics, 23 (2): 386-403.

Immink, M., E. Kennedy, and R. Sibrian (1995). 'Export Vegetable Crops and Poverty Alleviation for Smallholder Farm Households: A Case Study from Guatemala'. Paper presented at the Workshop on Poverty Alleviation through International Trade, UNCTAD, Santiago, Chile, 10-13 January.

International Monetary Fund (2005). International Financial Statistics Yearbook, Volume 58. Washington, DC: IMF, Statistics Department.

Katz, E. (1992). 'Intra-Household Resource Allocation in the Guatemalan Central Highlands: the Impact of Non-Traditional Agricultural Exports'. PhD dissertation, University of Wisconsin. 
Kebede, Y., K. Gunjal, and G. Coffin (1990). 'Adoption of New Technologies in Ethiopian Agriculture: The Case of Tegulet-Bulga District, Shoa Province'. Agricultural Economics, 4: 27-43.

Kiefer, N. M. (1988). 'Economic Duration Data and Hazard Function'. Journal of Economic Literature, 27(2): 646-679.

Lancaster, T. (1990). The Econometric Analysis of Transition Data. Cambridge: Cambridge University Press.

Mohr, L. B. (1982). Explaining Organizational Behavior. San Fransisco: Jossey-Bass.

Nissanke, M. and E. Thorbecke (2007). The Impact of Globalization on the World's Poor: Transmission Mechanisms. Basingstoke: Palgrave Macmillan.

Rahm, M. and W. Huffman (1984). 'The Adoption of Reduced Tillage: The Role of Human Capital and Other Variables'. American Journal of Agricultural Economics, 66(4): 405-413.

Ravallion, M. and S. Chen (2004). 'China's (Uneven) Progress Against Poverty'. World Bank Policy Research Working Paper 3408. Washington, DC: World Bank.

Ravallion, M. (2005). 'Evaluating Anti-poverty Programs'. Policy Research Working Paper Series 3625. Washington, DC: World Bank.

Thrupp, L. A., G. Bergeron, and W. Waters (1995). 'Bittersweet Harvests for Global Supermarkets: Challenges in Latin America's Agricultural Export Boom'. Washington, DC: World Resource Institute.

von Braun, J., D. Hotchkiss, and M. Immink (1989). 'Nontraditional Export Crops in Guatemala: Effects on Production, Income, and Nutrition'. Research Report 73. Washington, DC: IFPRI.

Waktola, A. (1980). 'Assessment of the Diffusion and Adoption of Agricultural Technologies and Chilalo'. Ethiopian Journal of Agricultural Science, 2: 51-68.

Winters, P., C. Crissman, and P. Espinoza (2004). 'Inducing the Adoption of Conservation Technologies: Lessons from the Ecuadorian Andes'. Environment and Development Economics, 9(5): 697-719.

Yirga, C., B. I. Shapiro, and M. Demeke (1996). 'Factors Influencing Adoption of New Wheat Technologies in Wolmera and Addis Alem Areas of Ethiopia'. Ethiopian Journal of Agricultural Economics, 1: 63-84. 